\title{
Use of sodC versus ctrA for real-time polymerase chain reaction-based detection of Neisseria meningitidis in sterile body fluids
}

\author{
Fábio Takenori Higa ${ }^{1 /+}$, Lucila Okuyama Fukasawa ${ }^{1}$, Maria Gisele Gonçalves ${ }^{1}$, \\ Maristela Marques Salgado', Ana Paula Silva de Lemos², Lee H Harrison', \\ Priscilla Lima de Oliveira' ${ }^{1}$ Carla Naufal da Silva', Claudio Tavares Sacchi' ${ }^{1}$ \\ ${ }^{1}$ Centro de Imunologia ${ }^{2}$ Centro de Bacteriologia, Instituto Adolfo Lutz, São Paulo, SP, Brasil ${ }^{3}$ nfectious Diseases Epidemiology \\ Research Unit, Graduate School of Public Health, School of Medicine, University of Pittsburgh, Pittsburgh, PA, USA
}

We evaluated the use of a newly described sodC-based real-time-polymerase chain reaction (RT-PCR) assay for detecting Neisseria meningitidis in normally sterile sites, such as cerebrospinal fluid and serum. The sodC-based RT-PCR assay has an advantage over ctrA for detecting nongroupable N. meningitidis isolates, which are commonly present in asymptomatic pharyngeal carriage. However, in our study, sodC-based RT-PCR was $7.5 \%$ less sensitive than ctrA. Given the public health impact of possible false-negative results due to the use of the sodC target gene alone, sodC-based RT-PCR for the diagnosis of meningococcal meningitis should be used with caution.

Key words: sodC-based RT-PCR - N. meningitidis diagnostics - meningitis

Meningococcal disease (MD) is a serious and often fatal infection. In Brazil, approximately 3,200 new cases of sporadic and outbreak-associated MD are reported each year, making this disease an important public health concern. Our laboratory at Adolfo Lutz Institute (IAL) uses a multiplex real-time-polymerase chain reaction (RT-PCR) assay developed and performed at IAL (Sacchi et al. 2011). The assay is composed of three sets of primers and three probes targeting the ctrA gene of Neisseria meningitidis (Mothershed et al. 2004), the lytA gene of Streptococcus pneumoniae (Carvalho et al. 2007) and the bexA gene of Haemophilus influenzae (Corless et al. 2001). ctrA is a frequently targeted gene used to detect $N$. meningitidis using RT-PCR (Corless et al. 2001, Mothershed et al. 2004). However, the capsule locus, including ctrA, is subject to rearrangement (Swartley et al. 1997, Clauds et al. 2002, Dolan-Livengood et al. 2003, Sadler et al. 2003) and 16\% or more of carried meningococci have been shown to lack ctrA altogether (Clauds et al. 2002, Dolan-Livengood et al. 2003).

It has been suggested that invasive meningococci can undergo similar rearrangements of the capsule region. For these reasons, a new target based on the sodC gene in meningitidis RT-PCR has been proposed as an alternative for clinical specimens, such as cerebrospinal fluid (CSF) and serum (Thomas et al. 2011, WHO 2011).

The possibility of false-negative results due to the use of the $c t r A$ target gene alone led us to investigate the sensitivity of $s o d C$-based RT-PCR by including it in our routine diagnosis of bacterial meningitis for eight months. We analysed 1,538 clinical samples [957 (62\%) CSF and $581(38 \%)$ sera] that were submitted for diag-

Financial support: NIAID (K24 AI52788), FIC/GID, NIH, University of Pittsburgh (D43TW006592)

+ Corresponding author: higa.fabio@yahoo.com.br

Received 13 August 2012

Accepted 6 February 2013 nostic testing for bacterial meningitis between JanuaryAugust 2011. The research protocol was approved by the IAL Institutional Ethical Committee.

CSF and blood culture is the "gold standard method" for diagnosing bacterial meningitis. In Brazil, culture is performed at each hospital and the isolates are sent to IAL for confirmation. For several reasons, including previous antibiotic treatment, most of the cases are not culture confirmed and, for many samples, culture is not performed. Because it is difficult to evaluate a diagnostic test without comparing it to a "gold standard", we tested all $\operatorname{ctr} A$-positive samples for the presence of a second meningococcal gene target (genogrouping).

We used a $\operatorname{ctr} A$-based multiplex RT-PCR (Sacchi et al. 2011) and a sodC-based monoplex RT-PCR (Thomas et al. 2011, WHO 2011) to detect $N$. meningitidis and a capsule gene-based RT-PCR for meningococcal genogrouping (Mothershed et al. 2004). DNA was extracted using a MagNA Pure LC and the DNA Isolation Kit III according to the manufacturer's instructions (Roche Diagnostic GmbH, Mannheim, Germany). All extracted DNA was stored at $-20^{\circ} \mathrm{C}$. The assays were performed in a $25 \mu \mathrm{L}$ reaction volume using TaqMan Universal Master Mix (Applied Biosystems, Foster City, CA) with $5 \mu \mathrm{L}$ of extracted DNA. Forward primer, reverse primer and the probe for each gene target were used at previously described concentrations.

All reactions were run in duplicate using an Applied Biosystems 7500 Real-Time PCR System (Applied Biosystems Foster City, CA, USA) with the following cycling parameters: $50^{\circ} \mathrm{C}$ for $2 \mathrm{~min}, 95^{\circ} \mathrm{C}$ for $10 \mathrm{~min}$ and 45 cycles of $95^{\circ} \mathrm{C}$ for $15 \mathrm{~s}$ and $60^{\circ} \mathrm{C}$ for $1 \mathrm{~min}$. Extension at $55^{\circ} \mathrm{C}$ for $1 \mathrm{~min}$ was used for RT-PCR genogrouping for serogroups B, W135 and Y. Positive and negative controls were included in each run.

A review of the literature showed that no standards exist for determining what criteria indicate a positive result. Some researchers established a "cut-off" cycle threshold $(\mathrm{Ct})$ value for a particular assay, while others considered any amplification signal, regardless of the $\mathrm{Ct}$ 
value, indicative of a positive result. However, the rationale for determining such parameters was not always clear. In this study, a positive result was defined as a Ct $\leq 38$ and a negative result as a $\mathrm{Ct}$ value of zero or $\geq 39$. All inconclusive results and inconsistent replicates were repeated. The lower limit of detection (LLD) for $\operatorname{sod} C$ and $\operatorname{ctr} A$ RT-PCR assays at a $\mathrm{Ct}$ of 38 was $200 \mathrm{fg}$. The efficiency of both reactions was similar: $92.15 \%$ for $c t r A$ and $90.42 \%$ for sodC.

The results were classified into four groups: Group A, positive for both ctrA and $\operatorname{sod} C$, Group B, positive for ctrA and negative for $\operatorname{sod} C$, Group C, negative for ctrA and positive for $\operatorname{sod} C$, and Group D, negative for both ctrA and $\operatorname{sod} C$ (Table). All samples that were positive for $\operatorname{sod} C$ were also positive for ctrA (Group A), but 24 samples that were positive for $\operatorname{ctr} A$ were negative for $\operatorname{sod} C$ (Group B). The Ct values of ctrA and $\operatorname{sod} C$ for each sample in Group A were mostly similar, varying from 23-38. To compare our results with the original paper that described the use of sodC for detecting $N$. meningitidis (Thomas et al. 2011), we also used a second Ct value of $\leq 35$ to define a positive result. We were only able to obtain culture results for 75 samples (51 from Group A and 24 from Group B).

Group A - Among the 295 Group A samples, 87.1\% (257/295) had a Ct $\leq 35$ for both sodC and ctrA, 7.8\% $(23 / 295)$ had a $\operatorname{ctr} A \mathrm{Ct} \leq 35$ and a $\operatorname{sod} C \mathrm{Ct} \geq 36$ (10 that were culture-confirmed) and 5.1\% (15/295) had a Ct $\geq 36$ (8 that were culture-confirmed) for both sodC and ctrA. Therefore, 38 Group A samples (18 culture-confirmed) were considered negative using a $\operatorname{sod} C \mathrm{Ct} \leq 35$ to define a positive result.

Group B - Among the 24 Group B samples, seven had ctrA $\mathrm{Ct}$ values $\leq 35: \mathrm{Ct}=29,31,32$ and 33 ( 1 of each) and $\mathrm{Ct}=35(\mathrm{n}=3)$. Additionally, $42 \%(10 / 24)$ were isolated from the CSF and 58\% (14/24) were isolated from the serum. No samples had less than the ideal volume. Three of 24 samples that were culture confirmed had ctrA Ct values of 35, 36 and 37 and the whole-cell suspensions made from the three isolates were positive for $\operatorname{ctr} A$ and $\operatorname{sod} C$.

We were able to determine the genogroup of all 319 ctrA-positive samples (Groups $\mathrm{A}$ and $\mathrm{B}$ ): $17.2 \%$ were genogroup B $(\mathrm{n}=55), 76.5 \%$ were genogroup C $(\mathrm{n}=$ $244), 3.8 \%$ were genogroup $\mathrm{W}(\mathrm{n}=12)$ and $2.5 \%$ were genogroup $\mathrm{Y}(\mathrm{n}=8)$.

A sodC-based RT-PCR assay has an advantage over ctrA in detecting nongroupable $N$. meningitidis isolates,

TABLE

Real-time-polymerase chain reaction results for $c t r A$ and $s o d C$

\begin{tabular}{lccc}
\hline Group & ctrA & sodC & $\mathrm{n}(\%)$ \\
\hline A & Positive & Positive & $295(19.2)$ \\
B & Positive & Negative & $24(1.6)$ \\
C & Negative & Positive & $0(0)$ \\
D & Negative & Negative & $1,219(79.2)$ \\
\hline Total & & & $1,538(100)$ \\
\hline
\end{tabular}

which are common in asymptomatic pharyngeal carriage. However, in our study, sodC-based RT-PCR was $7.5 \%$ less sensitive than ctrA in normally sterile body fluids. Our data are discordant from those previously reported by Thomas et al. in 2011. According to our data, there was no suggestion that these differences may be due to sample type or volume or differences in the LLD. Unfortunately, we could not determine the reasons for these differences. However, we analysed a much larger and more diverse collection representing 220 health care units distributed throughout the state of São Paulo.

Given the public health impact of possible falsenegative results due to the use of the sodC target gene alone, using sodC-based RT-PCR to detect $N$. meningitidis should be performed with caution.

\section{REFERENCES}

Carvalho MG, Tondella ML, McCaustland K, Weidlich L, McGee L, Mayer LW, Steigerwalt A, Whaley M, Facklam RR, Fields B, Carlone G, Ades EW, Dagan R, Sampson JS 2007. Evaluation and improvement of real-time PCR assays targeting lytA, ply and psaA genes for detection of pneumococcal DNA. J Clin Microbiol 45: 2460-2466.

Clauds H, Maiden MC, Maag R, Frosch M, Vogel U 2002. Many carried meningococci lack the genes required for capsule synthesis and transport. Microbiology 148: 1813-1819.

Corless CE, Guiver M, Borrow R, Edwards-Jones V, Fox AJ, Kaczmarski EB 2001. Simultaneous detection of Neisseria meningitidis, Haemophilus influenzae and Streptococcus pneumoniae in suspected cases of meningitis and septicemia using real-time PCR. J Clin Microbiol 39: 1553-1558.

Dolan-Livengood JM, Miller YK, Martin LE, Urwin R, Stephens DS 2003. Genetic basis for nongroupable Neisseria meningitidis. J Infect Dis 187: 1616-1628.

Mothershed EA, Sacchi CT, Whitney AM, Barnett GA, Ajello GW, Schmink S, Mayer LW, Phelan M, Taylor Jr TH, Bernhardt SA, Rosenstein NE, Popovic T 2004. Use of real-time PCR to resolve slide agglutination discrepancies in serogroup identification of Neisseria meningitidis. J Clin Microbiol 42: 320-328.

Sacchi CT, Fukasawa LO, Gonçalves MG, Salgado MM, Shutt KA, Carvalhanas TR, Ribeiro AF, Kemp B, Gorla MCO, Albernaz RK, Marques EGL, Cruciano A, Waldman EA, Brandileone MCC, Harrison LH, São Paulo RT-PCR Surveillance Project Team 2011. Incorporation of real-time PCR into routine Public Health Surveillance of culture negative bacterial meningitis in São Paulo, Brazil. PLoS ONE 6: 1-8.

Sadler F, Fox A, Neal K, Dawson M, Cartwright K, Borrow R 2003. Genetic analysis of capsular status of meningococcal carrier isolates. Epidemiol Infect 130: 59-70.

Swartley JS, Marfin AA, Edupuganti S, Liu LJ, Cieslak P, Perkins B, Wenger JD, Stephens DS 1997. Capsule switching of Neisseria meningitidis. Proc Natl Acad Sci USA 94: 271-276.

Thomas JD, Hatcher CP, Satterfield DA, Theodore MJ, Bach MC, Linscott KB, Zhao X, Wang X, Mair R, Schmink S, Arnold KE, Stephens DS, Harrison LH, Hollick RA, Andrade AL, LamaroCardoso J, de Lemos APS, Gritzfeld J, Gordon S, Soysal A, Bakir M, Sharma D, Jain S, Satola SW, Messonnier NE, Mayer LW 2011. sodC-based real-time PCR for detection of Neisseria meningitidis. PLoS ONE 6: e19361.

WHO - World Health Organization 2011. Epidemiology of meningitis caused by Neisseria meningitidis, Streptococcus pneumoniae and Haemophilus influenzae. In Laboratory methods for the diagnosis of meningitis caused by Neisseria meningitidis, Streptococcus pneumoniae and Haemophilus influenza, 2nd ed., WHO, Geneve, 116-167. 